University of Nebraska - Lincoln

DigitalCommons@University of Nebraska - Lincoln

Educational Psychology Papers and

Publications

Educational Psychology, Department of

December 2004

From inference to reasoning: The construction of rationality

David Moshman

University of Nebraska-Lincoln, dmoshman1@unl.edu

Follow this and additional works at: https://digitalcommons.unl.edu/edpsychpapers

Part of the Educational Psychology Commons

Moshman, David, "From inference to reasoning: The construction of rationality" (2004). Educational Psychology Papers and Publications. 44.

https://digitalcommons.unl.edu/edpsychpapers/44

This Article is brought to you for free and open access by the Educational Psychology, Department of at DigitalCommons@University of Nebraska - Lincoln. It has been accepted for inclusion in Educational Psychology Papers and Publications by an authorized administrator of DigitalCommons@University of Nebraska - Lincoln. 


\title{
From inference to reasoning: The construction of rationality
}

\author{
David Moshman \\ University of Nebraska-Lincoln
}

\begin{abstract}
Inference is elementary and ubiquitous: Cognition always goes beyond the data. Thinking - including problem solving, decision making, judgment, planning, and argumentation - is here defined as the deliberate application and coordination of one's inferences to serve one's purposes. Reasoning, in turn, is epistemologically self-constrained thinking in which the application and coordination of inferences is guided by a metacognitive commitment to what are deemed to be justifiable inferential norms. The construction of rationality, in this view, involves increasing consciousness and control of logical and other inferences. This metacognitive conception of rationality begins with logic rather than ending with it, and allows for developmental progress without positing a state of maturity.
\end{abstract}

For Piaget, cognitive development was, at its core, the development of logicality, culminating in the formal operational logic that emerges in early adolescence (Inhelder \& Piaget, 1958). Piaget's theory of formal operations has been challenged by the results from two major bodies of literature. One, the early competence literature, purports to show that, contrary to Piaget, even preschool children are fundamentally logical. The other, the adult irrationality literature, purports to show that, contrary to Piaget, even adults are at best nonlogical, if not fundamentally illogical and thus irrational. If these literatures challenge Piaget's conception of formal operations, however, they seem to pose an equally serious challenge to each other. If preschool children are so logical, how could adults be so illogical?

The short answer, I think, is that logical inference is routine even among preschool children, but that logical reasoning, as I will define it in this article, continues to develop for many more years and remains imperfect even in adults.

Correspondence: David Moshman, Department of Educational Psychology, 230 Teachers College Hall, University of Nebraska-Lincoln, Lincoln, NE 68588, USA. Email: dmoshman1@unl.edu 
More generally, we will see how preschool logic and adult nonlogicality are consistent with each other and with developmental conceptions of progress in rationality.

\section{LOGIC AND RATIONALITY}

Is rationality nothing more than logic? According to Bickhard and Campbell (1996, pp. 400-401):

[W]hatever the merits of a 'mental logic' account of specific kinds of thinking at specific points in human development, it can't be telling the whole story about human reasoning. When broader historical and developmental trends are taken into account, it becomes clear why rationality cannot be simply assimilated to logicality. A system of formal logic already contains all of its valid theorems. Logical systems don't grow or become more powerful. Logical systems can't construct new logical systems more powerful than themselves. Yet the history of logic shows that human knowledge of logic and logical systems has developed (Bochenski 1970, Kneale and Kneale 1986) and that more and more powerful systems of logic have been discovered. If rationality simply means following the rules contained within a particular logical system, then the history of logic can't be rational!

Similarly, if being rational means being logical, the development of each individual's knowledge of logic can't be a rational process either ... .

Consistent with this view of rationality as something more than logic, developmental research indicates that a conception of rationality as logical inference would greatly overestimate the rationality of young children and greatly underestimate the extent of ongoing development in reasoning. In a series of two experiments, for example, Pillow (2002) presented a total of 112 children, ranging in age from 5 through 10 years, with a series of inference tasks, including a deduction task in which they saw two toys of different colors, which were then hidden in two cans. After looking into one of the cans they were asked about the color of the toy in the other can. Every child, regardless of age, inferred the color correctly.

This result was no surprise to Pillow, whose concern was the development of metalogical understanding about deductive inferences (see below). In fact there is substantial evidence that preschool children routinely make deductive inferences (Braine \& O’Brien, 1998; Hawkins, Pea, Glick, \& Scribner, 1984; Scholnick \& Wing, 1995) and that even the behavior patterns of infants show an increasingly coordinated sensorimotor logic (Langer, 1980, 1986).

But even if there is a sense in which the behavior of an infant is in accord with strict rules of logic, the infant is not aware of that logic. Similarly, when preschool children reach correct conclusions, they don't even know they have made 
an inference, much less know anything about the nature, purpose, or justifiability of that inference. As we will see below, what develops beyond early childhood is not the basic ability to make logical inferences, but metalogical knowledge about the nature and justifiability of logical inferences, and metacognitive awareness, knowledge, and control of one's inferential processes.

If by rationality we mean conformity to rules of logic, then even preschool children are substantially rational in their inferential processes. If by rationality we mean metacognitive awareness, knowledge, and control of inferential processes, however, then rationality develops over a period of many years that often extends well beyond childhood without ever attaining a definitive state of maturity (Kuhn, 2000; Moshman, 1994). Such a conception does not deny an important role for logic but goes beyond logic in two ways. First, even within the logical domain, a metacognitive conception of rationality locates rationality in metalogical understanding and control rather than in logic per se. Second, a metacognitive conception acknowledges that rationality may develop through reflection on and coordination of heuristics and norms more subtle than the rules of formal logic. As we will see, this conception helps us understand how progress towards rationality is consistent with both logical competence in young children and inferential diversity among adults.

\section{INFERENCE, THINKING, AND REASONING}

Inference — going beyond the data - is elementary and ubiquitous. By the end of their first year, if not long before, infants infer what they will see from what they hear, and vice versa, infer the locations of objects from partial information, and infer people's emotions from their facial expressions. The uses of inference continue and expand with age. In reading and conversation we make inferences about meaning. In planning we make inferences about the future. In remembering we make inferences about the past. Cognition, in all its forms, is inferential.

Thinking is the deliberate application and coordination of one's inferences to serve one's purposes (Moshman, 1995, in press-a). We see this in problem solving, decision making, judgment, planning, argumentation, and other self-consciously inferential activities. What all of these have in common is metacognition, broadly construed to encompass "the achievement of increasing awareness, understanding, and control of one's own cognitive functions, as well as awareness and understanding of these functions as they occur in others" (Kuhn, 2000, p. 320). With the development of metacognition over the course of childhood and beyond, there is progress in the quality of our thinking, although this is not a matter of approaching some mature state of perfect thinking (Klaczynski, in press). 
Reasoning is epistemically self-constrained thinking (Moshman, 1995, in press-a). When thinkers constrain their inferences with the intent of conforming to what they deem to be appropriate inferential norms, they can be said to be reasoning. Reasoning, then, requires epistemic cognition-knowledge about the fundamental nature and justifiability of knowledge and inference.

Epistemic cognition has been the topic of substantial research and theory in developmental and educational psychology for the past several decades (Chandler, Hallett, \& Sokol, 2002; Hofer \& Pintrich, 1997, 2002; King \& Kitchener, 1994; Kuhn, Cheney, \& Weinstock, 2000). Epistemic development, it turns out, begins early and has a long history. Even preschool children, at least by age 4, understand that people lacking information may have, and act on the basis of, false beliefs (Flavell, Miller, \& Miller, 2002; Mitchell \& Riggs, 2000). Over the course of childhood, recognizing the inferential nature of their own cognitive processes, they construct a constructivist theory of mind. By late childhood, children understand that they are active constructors of knowledge (Chandler et al., 2002; Kuhn, 2000).

Although preadolescents are aware of, and have explanations for, differing interpretations in particular cases, they do not theorize about the nature, limits, and justification of knowledge in the abstract. Adolescents and adults, however, construct explicit epistemologies (Chandler et al., 2002; Hofer \& Pintrich, 1997, 2002; King \& Kitchener, 1994; Kuhn et al., 2000). The first to appear, and one common among adolescents and adults of all ages, is an objectivist epistemology, in which ultimate truth is deemed to be directly observable, provable, and/ or known to the authorities. Differences of opinion can only be the result of mistakes. Recognizing the intrinsic subjectivity of knowledge, however, some people construct subjectivist epistemologies, in which truth, which is constructed from individual and/or cultural perspectives, is deemed to be determined by, and thus relative to, such perspectives. Finally, recognizing the nihilistic and self-refuting nature of radical subjectivism, some people construct rationalist epistemologies that, without any claim to absolute or final truth, posit that ideas and viewpoints can be meaningfully evaluated, criticized, and justified.

Any epistemology provides a basis for reasoning-for deliberately constraining one's inferential processes in the name of truth. Rationalist epistemologies presumably support better reasoning than objectivist or subjectivist epistemologies, but there are many rationalist epistemologies, many forms of advanced reasoning, and many bases for error and misjudgment. Thus development proceeds from inference to thinking to reasoning, but these are not stages in any simple sense. Thinking and reasoning develop throughout childhood and often well beyond, and there is always room for greater consciousness of how one is making one's inferences and why. 


\section{THE DEVELOPMENT OF METALOGICAL UNDERSTANDING}

As we have seen, there are a wide variety of justifiable inferences, providing a basis for broad conceptions of thinking, reasoning, and rationality that go far beyond the realm of logic. It seems clear, however, that logical inferences are, in some circumstances, among those that can be most convincingly justified, and that knowledge about the nature and use of such inferences is thus an important basis for reasoning. In this section we narrow our focus to consider an important aspect of epistemic development - the development of metalogical understanding (Moshman, 1990).

Metalogical understanding — conceptual knowledge about logic —includes (1) awareness of inference as a process that generates conclusions from premises; (2) understanding that some inferences are better than others; (3) knowledge about the logical properties of propositions, inferences, and arguments; and (4) conceptualizations of logic as an epistemic domain. Let us consider each of these in turn, beginning with awareness of inference and of the associated distinction between premises and conclusions.

People of all ages routinely construct structures of knowledge that include, but go beyond, available facts. This is a long-standing truism of cognitive psychology (Jenkins, 1974), and there is no doubt that it holds for children (Beal, 1990; Flavell et al., 2002). In reading a text, for example, readers make inferences as they read, such that textual information and associated inferences are intertwined, often inextricably, in the resulting mental representation. Having read that Alphaville is north of Boomtown, and that Boomtown is north of Metropolis, a reader may construct a mental representation of Alphaville north of Boomtown north of Metropolis and read off that Alphaville is north of Metropolis. From an external perspective we may observe that "Alphaville is north of Metropolis" is a conclusion inferred from "Alphaville is north of Boomtown" and "Boomtown is north of Metropolis". From the perspective of the reader, however, these are simply three facts that can be read off the mental representation constructed in the course of processing the text. There is often no need to distinguish conclusions from premises, and no awareness of the inferential processes that have generated the former from the latter.

Even when adults are unaware of their inferences, however, they are aware that they make inferences. Even when they fail to distinguish their conclusions from their premises, they understand, in principle, the distinction between these. Preschool children, in contrast, are not just unaware of particular inferences but seem unaware of inference itself. They don't simply lose track of what they have inferred from what; they fail to make a distinction between premises and conclusions. The difference is not that very young children are unable to make 
inferences or even that they are less likely than adults to do so. The difference is that very young children are unaware of inferential processes, both their own and those of others, and thus fail to distinguish the output of such processes from the input.

By age 6, however, children recognize inference as a potential source of knowledge for both themselves and others (Keenan, Ruffman, \& Olson, 1994; Miller, Hardin, \& Montgomery, 2003; Pillow, 1999, 2002; Pillow, Hill, Boyce, \& Stein, 2000; Sodian \& Wimmer, 1987). Sodian and Wimmer (1987) devised a simple but revealing methodology for assessing young children's awareness of inference. Imagine that you are presented with a container of red balls. A ball is then removed from this container and placed in an opaque bag without your seeing which ball was transferred. Despite the absence of perceptual input, you readily infer that the ball in the bag is red. Moreover, because you are aware that this conclusion can be inferred, you recognize that another person who also did not see the transfer will make the same inference you did and will know the color of the ball in the bag without having seen it.

Sodian and Wimmer presented variations on this task, including a variety of control tasks, to children aged 4 to 6 years. They found that children of 4 or 5 years routinely made correct inferences about the color of the ball in the bag but showed no recognition that another person could infer that color. Even when the other person correctly indicated the color of the ball, they attributed this to a lucky guess. In contrast, 6-year-olds not only made the correct inference but recognized that the other person would make the same inference and thus, despite not having seen the ball in the bag, would know its color. In a variation of the task involving nonidentical objects in the original container, moreover, 6year-olds recognized that the other person would not be able to infer the color of the transferred object. Even though they themselves had seen and thus knew the color of the transferred object, they understood that the other person would not have that knowledge.

Even the 4-year-olds in Sodian and Wimmer's study, however, understood that perception could be a source of knowledge - that a person who had seen the transferred ball would know its color even if they themselves did not. This result is consistent with extensive research on early theories of mind showing that preschool children, beginning at age 4, understand that what a person knows is a function of what the person has seen, and that people with different perceptual access may thus have different beliefs, including false beliefs (Mitchell \& Riggs, 2002). Although it has been suggested that children as young as age 4 also have some awareness of inference as a source of knowledge (Keenan et al., 1994), the evidence for this is open to serious question (Pillow, 1999). Most subsequent research has confirmed that awareness of inference begins to be seen at age 6 , 
and there is evidence that even 6-year-olds are sometimes oblivious to inferences recognized by older children. Awareness of inference apparently emerges about age 6, later than what is commonly called "theory of mind", and continues to develop through the childhood years (Beal, 1990; Miller et al., 2003; Pillow, 1999, 2002; Pillow et al., 2000).

Awareness of inference allows one to consider the possibility that some inferences are better than others, in the epistemic sense that the conclusions they generate are more justifiable. In a series of two experiments, Pillow (2002) presented sets of inference-related tasks to 112 children, ranging in age from 5 to 10 years, and to 16 college undergraduates. The tasks included deductive inference, inductive inference, guessing on the basis of partial information, and pure guessing. Children of all ages, as well as adults, were highly certain of their conclusions in the case of deductive inferences and less certain in the case of nondeductive inferences and guesses. Even the youngest children (ages 5-6) had significantly more confidence in deductions than in guesses and justified their deductive conclusions by referring to relevant premises. By ages 8-10, children had significantly more confidence in deduction than induction and significantly more confidence in induction than in pure guessing. Adults showed a clear hierarchy with certainty significantly higher for deductive than for inductive inferences, for inductive inferences than for informed guesses, and for informed guesses than for pure guesses. Related research is consistent with the conclusion that children have at least some intuition of the greater certainty associated with deduction as early as age 5 or 6 , but that understanding of various metalogical distinctionsdeduction versus induction, inference versus guessing, informed versus pure guessing - continues to develop across childhood and beyond (Galotti, Komatsu, \& Voeltz, 1997; Pillow et al., 2000).

Deductive inferences are not just better than nondeductive inferences in the sense of allowing a somewhat higher level of certainty, however. In the case of a deductive inference, the conclusion follows necessarily from the premises. Motivated initially by the centrality of necessity in Piaget's $(1987,2001)$ theory (Smith, 1993), there has been substantial research on the development of conceptions of necessity. Miller, Custer, and Nassau (2000), for example, interviewed 100 children of ages 7, 9, and 11 about logical necessities (e.g., a light must be on or not on), mathematical necessities (e.g., 3 is bigger than 2), definitional necessities (e.g., triangles have three sides), physical laws (e.g., letting a pencil go will result in it falling), social conventions (e.g., students wear shoes in school), and an arbitrary fact (whether there was chalk in a particular box). Questions focused on spatial universality ("Is this true everywhere?"), changeability ("Could this ever change?"), and the imaginability of any alternative (including, for a sample of items, a request to draw an alternative such as "a triangle that does 
not have three sides"). Even the 7-year-olds showed some appreciation of necessary truths as holding everywhere and never changing. With increasing age, children made increasingly sophisticated differentiations among the various sorts of knowledge and increasingly recognized that violations of necessary truths were literally unimaginable.

Other research has generated results consistent with this picture. Children show some understanding of logical necessity, consistency, and impossibility beginning about age 6 (Ruffman, 1999; Somerville, Hadkinson, \& Greenberg, 1979; Tunmer, Nesdale, \& Pratt, 1983). Research also shows continuing development in the comprehension of necessity, possibility, sufficiency, indeterminacy, and associated concepts over the remaining years of childhood (Byrnes \& Beilin, 1991; Morris \& Sloutsky, 2001; Piaget, 1987; Pieraut-Le Bonniec, 1980; Ricco, 1997; Ricco, McCollum, \& Wang, 1997), and age-related constraints on the ability to learn such concepts (Klahr \& Chen, 2003).

Not surprisingly, the development of metalogical understanding continues into adolescence. Consider the following arguments, each consisting of two premises and a conclusion:

1. Elephants are plants or animals.

Elephants are not plants.

Therefore, elephants are animals.

2. Elephants are animals or plants.

Elephants are not animals.

Therefore, elephants are plants.

Even a young child would readily endorse the first argument as logical. Children as old as age 9 or 10, however, reject arguments such as \#2 as illogical (Moshman \& Franks, 1986). Most adolescents and adults, on the other hand, especially given sufficient opportunity to consider their responses, recognize in cases of this sort that the two arguments have the same logical form and are both valid. The second argument has a false second premise and a false conclusion, which is why children reject it, but it is nonetheless a valid argument in that the conclusion follows necessarily from the two premises. If the premises were true, the conclusion would necessarily be true as well.

This age difference does not reflect an inability of children with regard to particular logical forms. Very young children routinely make instantaneous deductions without even realizing they have done so. But that's precisely the problem. Lacking awareness of inference, they cannot explicitly evaluate arguments. Even as children gain some degree of awareness of and control over their inferences, they initially remain oblivious to the logical form of those inferences. They make disjunctive inferences, for example, without explicit awareness of 
the logical form of disjunctive arguments. Lacking explicit awareness of logical form, children do not distinguish form from content and thus remain centered on immediate inferences from empirically acceptable propositions (see Harris \& Leevers, 2000, for research on counterfactual inference in young children, and Simoneau \& Markovits, 2003, for research on the complexities of subsequent development).

As children approach adolescence they increasingly distinguish form from content, and thus can recognize valid arguments even in the case of arguments containing false premises and/or a false conclusion (Morris, 2000). At relatively advanced levels of metalogical understanding, typically beginning about age 11, it becomes possible to recognize and evaluate the logical interconnections among propositions that are hypothetical or even false (Efklides, Demetriou, \& Metallidou, 1994; Franks, 1996, 1997; Markovits \& Bouffard-Bouchard, 1992; Markovits \& Nantel, 1989; Markovits \& Vachon, 1989; Moshman \& Franks, 1986). As a result, adolescents and adults are able to consider the potential interrelations of multiple possibilities and thus to formulate and test explicit theories (Inhelder \& Piaget, 1958; Kuhn, Amsel, \& O’Loughlin, 1988; Moshman, 1998, in press-a; Zimmerman, 2000).

Even in early childhood, then, automatic inferences are routine. In middle childhood there is awareness of, and increasing knowledge about, inference. Adolescents and adults, notwithstanding their many shortcomings, routinely show systematic forms of hypothetico-deductive reasoning not seen in children under the age of about 11. Is there still another stage, attained at least by some logicians, involving perhaps an explicit conception of logic as an epistemic domain, a mode of justification? Whether or not there is such a stage, or any highest stage, each stage in the sequence represents an advance in consciousness and control of logic, and thus a higher level of rationality than the stage from which it emerged.

\section{UNIVERSALITY AND DIVERSITY}

Piaget famously posited a universal sequence of stages culminating in a universal state of maturity - formal operations (Inhelder \& Piaget, 1958). In a universalist stage model such as Piaget's, each stage can only emerge from the previous one, and the limitations of each stage, if they are ever to be understood, can only be understood from the perspective of the next, so development proceeds in a predictable sequence, with the highest stage defining the state of maturity. Individuals may differ in the rate and extent of development, but development, to the extent that it occurs, can only proceed along a single path.

Research on the development of metalogical understanding suggests a picture consistent with a universalist stage model. Preschool children make infer- 
ences but are not aware of doing so. Beginning at about age 6 , children become aware of inference, increasingly understand that some inferences are better than others, increasingly recognize the necessity of deductive inferences, and increasingly comprehend associated forms of necessity, possibility, and impossibility. Beginning at about age 11, at least some individuals attain a more explicit understanding of the role of logical form in guaranteeing the validity of deductive arguments and show increasingly systematic reasoning with hypothetical and false premises. The three stages run parallel, in important ways, to Piaget's preoperational, concrete operations, and formal operations stages, and it seems plausible that they form an invariant sequence. That is, children make inferences before they come to understand the logical properties of inferences, and they understand those properties before they apply such metalogical understanding in hypothetical contexts. Moshman (1990) provides a metacognitive account of such a sequence, including a fourth stage that reflects on the third from the standpoint of a logician.

As we have seen, however, logical inferences are not the only legitimate inferences. Rationality includes metacognitive knowledge and control of a variety of inferences. Rationality is thus much richer than logic, and its development can be expected to be more diverse.

Many theorists have suggested that human inferential processes are usefully construed as comprising two fundamental systems (Evans, 2002; Kahneman, 2003; Klaczynski, 2000, 2001, in press; Sloman, 1996; Stanovich, 1999; Stanovich \& West, 2000). Although the distinction between the systems can be, and has been, formulated in a variety of ways, one system is generally seen as analytical, involving the strict application of logic and other mechanistic systems of formal rules, and the other as heuristic, involving processes that are associative, holistic, flexible, and sensitive to context. The distinction between two inferential systems raises questions about the locus of diversity. One possibility is that some groups of people are oriented towards analytic processing and other groups towards heuristic processing. Another possibility is that individuals differ in this regard but that such differences exist mostly within, rather than across, abstract social groups. A third possibility is that inferential diversity exists mostly within, rather than across, individuals. Diversity, in other words, may exist primarily across groups, across individuals, or within individuals.

Theorists of group differences fall into two categories - those highlighting culture and those highlighting gender. Cultural difference theorists construe current evidence as showing categorical distinctions in inference, thinking, and reasoning across discrete cultural groups (Nisbett, Peng, Choi, \& Norenzayan, 2001; Peng \& Nisbett, 1999). Nisbett et al. (2001, p. 291, italics in original), for example, 
... find East Asians to be holistic, attending to the entire field and assigning causality to it, making relatively little use of categories and formal logic, and relying on "dialectical" reasoning, whereas Westerners are more analytic, paying attention primarily to the object and the categories to which it belongs and using rules, including formal logic, to understand its behavior. The 2 types of cognitive processes are embedded in different naive metaphysical systems and tacit epistemologies.

Interestingly, this distinction parallels one commonly made by some feminist theorists with regard to what they see as a categorical distinction between male and female reasoning. Construing logic as masculine, gender difference theorists have argued that the equation of rationality with logic is central to the oppression of women because men, who tend to be logical, are thereby deemed rational, whereas women, who tend towards inferential processes that are more holistic, flexible, and contextual, are thereby deemed less rational (Oliver, 1991; Orr, 1995). Given the existence of males and females in all cultures, it is unclear how the positions of the cultural difference theorists and the gender difference theorists can be reconciled. For the most part these two subcategories of group difference theorists appear unaware of each other and do not address each other's views.

Claims of categorical group differences in inferential processes can turn out to be false if research shows there is really only one mode of processing-for example, if seemingly heuristic inferences always turn out to be logical after all. However, even when the inferential diversity is real-as it seems in this case to be - there are two ways in which claims of categorical group differences can turn out to be wrong. With regard to the standard analytic vs. heuristic dichotomy, one possibility is that there are indeed some people who can be deemed analytical/ formal thinkers and others who can be deemed heuristic/contextual thinkers, but that both types of people are commonly found in the various groups alleged to be categorically different. Another possibility is that both modes of processing are common in most or all people. In this case, although we can still distinguish two types of thinking, a distinction between two types of thinkers is more misleading than helpful.

Research supports the latter possibility. Both analytic/formal and heuristic/ contextual processes are commonly seen in most or all people (Evans, 2002; Klaczynski, 2000, 2001, in press; Stanovich, 1999; Stanovich \& West, 2000). There are indeed individual differences in the use of these processes, and some of these differences may be related to culture and/or gender, but neither East Asians, Westerners, women, nor men have been shown to rely on any particular kind of reasoning to the exclusion of any other kind. On the contrary, studies of thinking and reasoning routinely fail to find gender differences (Klaczynski, 2001), and even where cultural differences are found (Nisbett et al., 2001; Peng $\&$ Nisbett, 1999) they are virtually never categorical. Both analytic and heuris- 
tic processes are routine in most or all women and most or all men in most or all cultural contexts.

Inferential diversity, moreover, may be too rich to capture in a simple distinction between analytic and heuristic processes, or any other dichotomy. Moshman (1998) distinguished three forms of reasoning - case-based, law-based, and dialectical. This can be transformed into four by dividing case-based reasoning into (a) analogical reasoning, in which previous cases serve heuristic purposes, as in solving a problem by considering the solution to a similar one, and (b) precedentbased reasoning, in which earlier determinations constrain the legitimacy of later ones, as in the resolution of legal disputes in a system of case law. We can generate five categories of reasoning if we also subdivide law-based reasoning into (a) ruled-based reasoning, in which thinking is constrained by formal rules such as those of logic and mathematics, and (b) principled reasoning, in which thinking is constrained by abstract principles such as those associated with advanced moral understanding (Moshman, in press-b). Dialectical reasoning, in turn, takes multiple forms that can be sorted into any number of additional categories. Many researchers and theorists, moreover, see thinking as an ongoing interchange of multiple strategies which vary over time (Kuhn, Garcia-Mila, Zohar, \& Andersen, 1995; Siegler, 1996).

How many domains of inference or types of thinking or forms of reasoning are there? No matter how we put the question, there is no right answer. The impossibility of a right answer should not deter us from trying to develop taxonomies and theories of thinking and reasoning, but we should be wary of assumptions that there are precisely two kinds of thinking, or any other particular number.

In sum, research on thinking and reasoning demonstrates diversity within individuals, diversity of a sufficiently subtle sort that it cannot be reduced to some small number of definitive categories. This picture has important implications for understanding (a) human universality, (b) the process of thinking, and (c) the process of development.

Classic notions of universality, based on a universal logic that defines rationality, do not deny the possibility of erroneous inferential processes but are challenged by the existence of legitimate inferential diversity. It does not appear that Piaget's conception of formal operations, or any other logical structure, constitutes rational maturity. Interestingly, however, the fact that we all use diverse strategies and perspectives renders human diversity a human universal. Inferential diversity, it turns out, is a universal characteristic of human rationality.

Attention to internal diversity - the diversity within each of us - is important to understanding processes of thinking and development. Thinking, it appears, is not the deliberate application of the one true logic but rather involves the coordination of distinct inferential processes. Given the demands of such coordina- 
tion, it is to be expected that we would each, perhaps to varying degrees, develop metacognitive understanding and control of our diverse inferences.

The development of rationality, then, is not a matter of switching over from one sort of inferential system to another, as in a transition from heuristic to analytic processing. Rather it is a matter of increasing consciousness and control of multiple inferential processes, as in the coordination of heuristic and analytic processing. We are now prepared to consider developmental processes more directly.

\section{THE CONSTRUCTION OF RATIONALITY}

How do we come to be rational? As we have seen, far from being its culmination, logic comes early in the development of rationality. By the age of 4 , if not earlier, children routinely make logically correct verbal inferences. Increasingly sophisticated forms of logic can be identified, in fact, in the sensorimotor coordinations of infancy (Langer, 1980, 1986; Piaget, 1936/1963).

The transition from inference to reasoning, as we have seen, is not a transition from illogical inference to logical inference or from heuristic inference to analytic inference. Rather it is the development of increasingly explicit knowledge of properties implicit in the variety of inferences we already make. Novelty resides not in facts or skills that emerge from genes or are taken in from environments, but rather in emerging conceptual knowledge about inferential abilities we already had. It seems likely, then, that progress in reasoning and rationality comes about through reflection on our inferences. Such reflection, for example, might enable an individual to determine that a particular inference is logically necessary because there is only one possible conclusion, and further reflection may enable the formulation of a more general coordination of necessity and possibility (Piaget, 1987).

If the only legitimate inferences were those sanctioned by a particular logical system, ideal reasoning might consist simply of assimilating premises to that system. As we have seen, however, thinking and reasoning involve the coordination of diverse inferences. Reflection on reasoning, then, must include reflection on such coordinations, and may generate knowledge that facilitates and improves future coordinations. Thus the development of rationality is as much a process of coordination as a process of reflection, and these cannot be sharply distinguished (Piaget, 1985, 2001).

Reflection and coordination, moreover, often take place in the context of social interaction, and especially peer interaction. In social contexts we may find ourselves challenged to justify our conclusions, and thus to recognize and justify our inferences. We may also be challenged to understand the inferential paths that led others to alternative views, and to coordinate those inferences and con- 
clusions with ours. Thus social interaction may substantially encourage processes of reflection and coordination.

Not all social interactions promote rationality, however. If the interacting individuals differ in knowledge, authority, or power (as in child/adult, student/ teacher, and novice/expert interactions), the lower-status individual may simply accept the conclusions of the higher-status individual with little or no reflection on or coordination of inferential processes. Thus the kind of social interaction most likely to promote the construction of rationality may be peer interactionideally, interaction among individuals who are, and see themselves to be, comparable in knowledge, authority, and power.

Processes of reflection and coordination in the context of peer interaction are illustrated in a study by Moshman and Geil (1998) in which college students were presented with the original and most difficult version of the notorious selection task, which requires logical testing of an abstract hypothesis. Consistent with previous research, only 3 of the 32 students who worked individually correctly determined what evidence to seek. In sharp contrast, 15 out of the 20 groups of five or six students each who worked collaboratively made correct selections, even in cases where no member of a group initially gave the logical response, and individual members of these groups generally understood why their final selections were correct. Close examination of what happened within the groups showed a process of collaborative reasoning in which students presented, justified, criticized, compared, and combined a variety of ideas and possibilities until they achieved a structure of logical understanding that most or all members of the group understood and accepted.

In sum, the construction of rationality involves ongoing processes of reflection, coordination, and peer interaction (Moshman 1998, in press-a; Piaget, 1985 , 2001). These generate progress towards higher levels of metacognitive understanding and control of our inferential processes, but they do not culminate in any final logical structure. Whatever level of rationality we attain, further reflection on and coordination of our current skills and insights can enhance our (meta)rationality.

This is a constructivist view of the development of rationality in that it relies not on genetic or environmental forces but on self-regulated processes of reflection and coordination. Like Piaget's theory and other developmental versions of constructivism, the present view highlights the rationality of the constructive processes and their success in generating progress towards higher levels of rationality. Unlike Piaget's theory, however, the present view does not assume a universal sequence of general stages or a universal structure that constitutes maturity. Thus the present approach represents what I have elsewhere called pluralist rational constructivism (Moshman, in press-a). 


\section{THE UBIQUITY OF INFERENCE}

Developmental theories are theories of progress and thus highlight the ways we get better-more logical, more rational, or something of that sort. For a full view of human functioning, however, it is important to keep in mind that not everything changes, and that not all changes are good. Even as our abilities to think and reason improve with age, we continue throughout our lives to be driven by inferences beyond our present knowledge and control. Genetic considerations may be important in some cases, as in the universal human capacity for inferring emotions from the sight of human facial expressions. Cultural considerations, such as being indoctrinated in the ways and/or beliefs of a religious, political, or other group, may also drive systems of automatic inference and block ideologically unacceptable inferences. Even as we construct beliefs and values of our own, self-serving biases direct our inferences to avoid conflict with our identities (Klaczynski, 1997, 2000; Klaczynski \& Narasimham, 1998; Moshman, 2004).

With development we become conscious of some of our inferences and better control our beliefs and self-conceptions. Progress is always possible through reflection, coordination, and peer interaction, but we can never fully conceptualize and control our inferences. Even as we become conscious of the basis for some set of inferences, that consciousness itself generates new inferences of which we are not (yet) conscious.

Thinking and reasoning always arise in the context of diverse systems of inference that are deeply biological, cultural, and self-serving. Even as we progress towards greater rationality, thinking and reasoning remain just the tip of an inferential iceberg. Logic is elementary, and further development achievable, but rational maturity forever eludes us.

\section{REFERENCES}

Beal, C. R. (1990). Development of knowledge about the role of inference in text comprehension. Child Development, 61, 1011-1023.

Bickhard, M. H., \& Campbell, R. L. (1996). Developmental aspects of expertise: Rationality and generalization. Journal of Experimental and Theoretical Artificial Intelligence, 8, 399-417.

Bochenski, I. M. (1970). A history of formal logic. New York: Chelsea.

Braine, M. D. S., \& O’Brien, D. P. (Eds.). (1998). Mental logic. Mahwah, NJ: Lawrence Erlbaum Associates Inc.

Byrnes, J. P., \& Beilin, H. (1991). The cognitive basis of uncertainty. Human Development, 34, 189-203.

Chandler, M. J., Hallett, D., \& Sokol, B. W. (2002). Competing claims about competing knowledge claims. In B. K. Hofer \& P. R. Pintrich (Eds.), Personal epistemology: The 
psychology of beliefs about knowledge and knowing (pp. 145-168). Mahwah, NJ: Lawrence Erlbaum Associates Inc.

Efklides, A., Demetriou, A., \& Metallidou, Y. (1994). The structure and development of propositional reasoning ability: Cognitive and metacognitive aspects. In A. Demetriou \& A. Efklides (Eds.), Intelligence, mind, and reasoning: Structure and development (pp. 151-172). Amsterdam: North-Holland.

Evans, J. St. B. T. (2002). Logic and human reasoning: An assessment of the deduction paradigm. Psychological Bulletin, 128, 978-996.

Flavell, J. H., Miller, P. H., \& Miller, S. A. (2002). Cognitive development (4th ed.). Upper Saddle River, NJ: Prentice Hall.

Franks, B. A. (1996). Deductive reasoning in narrative contexts: Developmental trends and reading skill effects. Genetic, Social, and General Psychology Monographs, 122, $75-105$.

Franks, B. A. (1997). Deductive reasoning with prose passages: Effects of age, inference form, prior knowledge, and reading skill. International Journal of Behavioral Development, 21, 501-535.

Galotti, K. M., Komatsu, L. K., \& Voelz, S. (1997). Children's differential performance on deductive and inductive syllogisms. Developmental Psychology, 33, 70-78.

Harris, P. L., \& Leevers, H. J. (2000). Reasoning from false premises. In P. Mitchell \& K. J. Riggs (Eds.), Children's reasoning and the mind (pp. 67-86). Hove, UK: Psychology Press.

Hawkins, J., Pea, R. D., Glick, J., \& Scribner, S. (1984). "Merds that laugh don't like mushrooms": Evidence for deductive reasoning by preschoolers. Developmental Psychology, 20, 584-594.

Hofer, B. K., \& Pintrich, P. R. (1997). The development of epistemological theories: Beliefs about knowledge and knowing and their relation to learning. Review of Educational Research, 67, 88-140.

Hofer, B. K., \& Pintrich, P. R. (Eds.). (2002). Personal epistemology: The psychology of beliefs about knowledge and knowing. Mahwah, NJ: Lawrence Erlbaum Associates Inc.

Inhelder, B., \& Piaget, J. (1958). The growth of logical thinking from childhood to adolescence. New York: Basic Books.

Jenkins, J. J. (1974). Remember that old theory of memory? Well, forget it! American Psychologist, 29, 785-795.

Kahneman, D. (2003). A perspective on judgment and choice: Mapping bounded rationality. American Psychologist, 58, 697-720.

Keenan, T., Ruffman, T., \& Olson, D. R. (1994). When do children begin to understand logical inference as a source of knowledge? Cognitive Development, 9, 331-353.

King, P. M., \& Kitchener, K. S. (1994). Developing reflective judgment: Understanding and promoting intellectual growth and critical thinking in adolescents and adults. San Francisco: Jossey-Bass.

Klaczynski, P. A. (1997). Bias in adolescents' everyday reasoning and its relationship with intellectual ability, personal theories, and self-serving motivation. Developmental Psychology, 33, 273-283.

Klaczynski, P. A. (2000). Motivated scientific reasoning biases, epistemological beliefs, and theory polarization: A two-process approach to adolescent cognition. Child Development, 71, 1347-1366. 
Klaczynski, P. A. (2001). Analytic and heuristic processing influences on adolescent reasoning and decision-making. Child Development, 72, 844-861.

Klaczynski, P. A. (in press). Metacognitive and cognitive variability: A two-process model of decision making and its development. In J. E. Jacobs \& P. A. Klaczynski (Eds.), The development of decision making. Mahwah, NJ: Lawrence Erlbaum Associates Inc.

Klaczynski, P. A., \& Narasimham, G. (1998). Development of scientific reasoning biases: Cognitive versus ego-protective explanations. Developmental Psychology, 34, 175-187.

Klahr, D., \& Chen, Z. (2003). Overcoming the positive-capture strategy in young children: Learning about indeterminacy. Child Development, 74, 1275-1296.

Kneale, W., \& Kneale, M. (1986). The development of logic. Oxford: Clarendon.

Kuhn, D. (2000). Theory of mind, metacognition, and reasoning: A life-span perspective. In P. Mitchell \& K. J. Riggs (Eds.), Children's reasoning and the mind (pp. 301-326). Hove, UK: Psychology Press.

Kuhn, D. Amsel, E., \& O'Loughlin, M. (1988). The development of scientific thinking skills. San Diego, CA: Academic Press.

Kuhn, D., Cheney, R., \& Weinstock, M. (2000). The development of epistemological understanding. Cognitive Development, 15, 309-328.

Kuhn, D., Garcia-Mila, M., Zohar, A., \& Andersen, C. (1995). Strategies of knowledge acquisition. Monographs of the Society for Research in Child Development, 60, Serial No. 245.

Langer, J. (1980). The origins of logic: From six to twelve months. San Francisco: Academic Press.

Langer, J. (1986). The origins of logic: One to two years. Orlando, FL: Academic Press.

Markovits, H., \& Bouffard-Bouchard, T. (1992). The belief-bias effect in reasoning: The development and activation of competence. British Journal of Developmental Psychology, 10, 269-284.

Markovits, H., \& Nantel, G. (1989). The belief-bias effect in the production and evaluation of logical conclusions. Memory \& Cognition, 17, 11-17.

Markovits, H., \& Vachon, R. (1989). Reasoning with contrary-to-fact propositions. Journal of Experimental Child Psychology, 47, 398-412.

Miller, S. A., Custer, W. L., \& Nassau, G. (2000). Children's understanding of the necessity of logically necessary truths. Cognitive Development, 15, 383-403.

Miller, S. A., Hardin, C. A., \& Montgomery, D. E. (2003). Young children's understanding of the conditions for knowledge acquisition. Journal of Cognition and Development, 4 , $325-356$.

Mitchell, P., \& Riggs, K. J. (Eds.). (2000), Children's reasoning and the mind. Hove, UK: Psychology Press.

Morris, A. K. (2000). Development of logical reasoning: Children's ability to verbally explain the nature of the distinction between logical and nonlogical forms of argument. Developmental Psychology, 36, 741-758.

Morris, B. J., \& Sloutsky, V. (2001). Children's solutions of logical versus empirical problems: What's missing and what develops? Cognitive Development, 16, 907-928.

Moshman, D. (1990). The development of metalogical understanding. In W. F. Overton (Ed.), Reasoning, necessity, and logic: Developmental perspectives (pp. 205-225). Hillsdale, NJ: Lawrence Erlbaum Associates Inc. 
Moshman, D. (1994). Reason, reasons, and reasoning: A constructivist account of human rationality. Theory \& Psychology, 4, 245-260.

Moshman, D. (1995). Reasoning as self-constrained thinking. Human Development, 38 , 53-64.

Moshman, D. (1998). Cognitive development beyond childhood. In W. Damon (Series Ed.) \& D. Kuhn \& R. Siegler (Vol. Eds.), Handbook of child psychology: Vol. 2. Cognition, perception, and language (5th ed., pp. 947-978). New York: Wiley.

Moshman, D. (2004). False moral identity: Self-serving denial in the maintenance of moral self-conceptions. In D. Lapsley \& D. Narvaez (Eds.), Morality, self, and identity (pp. 83-109). Mahwah, NJ: Lawrence Erlbaum Associates Inc.

Moshman, D. (in press-a). Adolescent psychological development: Rationality, morality, and identity, (2nd ed.). Mahwah, NJ: Lawrence Erlbaum Associates Inc.

Moshman, D. (in press-b). Advanced moral development. In T. Wren, A. Tellings, \& W. van Haaften (Eds.), Moral sensibilities III: The adolescent. Bemmel, Netherlands:

Concorde.

Moshman, D., \& Franks, B. A. (1986). Development of the concept of inferential validity. Child Development, 57, 153-165.

Moshman, D., \& Geil, M. (1998). Collaborative reasoning: Evidence for collective rationality. Thinking \& Reasoning, 4, 231-248.

Nisbett, R. E., Peng, K., Choi, I., \& Norenzayan, A. (2001). Culture and systems of thought: Holistic versus analytic cognition. Psychological Review, 108, 291-310.

Oliver, P. (1991). 'What do girls know anyway?': Rationality, gender and social control. Feminism \& Psychology, 1, 339-360.

Orr. D. (1995). On logic and moral voice. Informal Logic, 17, 347-363.

Peng, K., \& Nisbett, R. E. (1999). Culture, dialectics, and reasoning about contradiction. American Psychologist, 54, 741-754.

Piaget, J. (1963). The origins of intelligence in children. New York: Norton. [Originally published 1936.]

Piaget, J. (1985). The equilibration of cognitive structures. Chicago: University of Chicago Press.

Piaget, J. (1987). Possibility and necessity. Minneapolis: University of Minnesota Press.

Piaget, J. (2001). Studies in reflecting abstraction. Hove, UK: Psychology Press.

Pieraut-Le Bonniec, G. (1980). The development of modal reasoning: Genesis of necessity and possibility notions. New York: Academic Press.

Pillow, B. H. (1999). Children's understanding of inferential knowledge. Journal of Genetic Psychology, 160, 419-428.

Pillow, B. H. (2002). Children's and adults' evaluation of the certainty of deductive inferences, inductive inferences, and guesses. Child Development, 73, 779-792.

Pillow, B. H., Hill, V., Boyce, A., \& Stein, C. (2000). Understanding inference as a source of knowledge: Children's ability to evaluate the certainty of deduction, perception, and guessing. Developmental Psychology, 36, 169-179.

Ricco, R. B. (1997). The development of proof construction in middle childhood. Journal of Experimental Child Psychology, 66, 279-310. 
Ricco, R. B., McCollum, D., \& Wang, J. (1997). Children's judgments of certainty and uncertainty on a problem where the possible solutions differ in likelihood. Journal of Genetic Psychology, 158, 401-410.

Ruffman, T. (1999). Children's understanding of logical inconsistency. Child Development, $70,872-886$.

Scholnick, E. K., \& Wing, C. S. (1995). Logic in conversation: Comparative studies of deduction in children and adults. Cognitive Development, 10, 319-345.

Siegler, R. S. (1996). Emerging minds: The process of change in children's thinking. Oxford: Oxford University Press.

Simoneau, M., \& Markovits, H. (2003). Reasoning with premises that are not empirically true: Evidence for the role of inhibition and retrieval. Developmental Psychology, 39, 964-975.

Sloman, S. A. (1996). The empirical case for two systems of reasoning. Psychological Bulletin, 119, $3-22$.

Smith, L. (1993). Necessary knowledge: Piagetian perspectives on constructivism. Hillsdale, NJ: Lawrence Erlbaum Associates Inc.

Sodian, B., \& Wimmer, H. (1987). Children's understanding of inference as a source of knowledge. Child Development, 58, 424-433.

Somerville, S. C., Hadkinson, B. A., \& Greenberg, C. (1979). Two levels of inferential behavior in young children. Child Development, 50, 119-131.

Stanovich, K. E. (1999). Who is rational? Studies of individual differences in reasoning. Mahwah, NJ: Lawrence Erlbaum Associates Inc.

Stanovich, K. E., \& West, R. F. (2000). Individual differences in reasoning: Implications for the rationality debate? Behavioral and Brain Sciences, 23, 645-665.

Tunmer, W. E., Nesdale, A. R., \& Pratt, C. (1983). The development of young children's awareness of logical inconsistencies. Journal of Experimental Child Psychology, 36, 97-108.

Zimmerman, C. (2000). The development of scientific reasoning skills Developmental Review, 20, 99-149. 